\title{
Speed scaling technique integrated in scheduling of production and maintenance under energy constraints using genetic algorithms
}

\author{
Sadiqi Assia ${ }^{1,2,}$, El Abbassi Ikram² ${ }^{2}$, El Barkany Abdellah ${ }^{1}$, Darcherif Moumen ${ }^{2}$ and El Biyaali Ahmed ${ }^{1}$ \\ ${ }^{1}$ Laboratoire Génie Mécanique, Faculté des sciences et Techniques de Fès, Université Sidi Mohammed Ben Abdellah, B.P. 2202 - \\ Route d'Imouzzer - Fès, Maroc \\ ${ }^{2}$ ECAM-EPMI, 13 Boulevard de l'Hautil, 95092 Cergy-Pontoise (France)
}

\begin{abstract}
Recently, energy scarcity and environmental pollution have become increasingly serious problems, while the scheduling of energy savings is attracting increasing attention from industries to minimize energy consumption. This article deals with the problem of scheduling production and maintenance under energy constraints in the flow shop. Two mixed binary integer programming models are provided to derive optimal scheduling to minimize total energy consumption (TEC). To solve this problem, we use an approximate method as a genetic algorithm (GA).
\end{abstract}

\section{Introduction}

It is certainly indisputable that the climate changes induced by this increase in the concentration of greenhouse gases will have multiple consequences that are still difficult to identify. However, they are expected to cause regional and global changes in temperature, precipitation and other climate variables, which could result in global changes in soil moisture, rising mean sea level and the prospect of more severe episodes of extreme heat, flooding and drought.

Excessive emissions of greenhouse gases and in particular carbon dioxide produced by the combustion of fossil fuels. Although fossil fuels have been widely used for electricity production, rational use of energy will contribute to a significant reduction in carbon emissions. Manufacturing industry has always been a major consumer of energy. As a result, modern government regulations have forced manufacturers to adopt energysaving measures [1]. In particular, the researchers understood that scheduling could play an important role in reducing the energy consumption of manufacturing processes. Therefore, operational research tools and metaheuristic research methods, such as genetic algorithm [2], particle swarm optimization [3] and simulated annealing [4], are also used for the design of a cleaner production system.

The purpose of this article is to establish two models for integrated scheduling of production and maintenance tasks, in order to minimize total energy consumption. We use an approximate method as a genetic algorithm (GA).

\section{PROBLEM DESCRIPTION}

This section addresses the problems of integrated scheduling of fixed and flexible production and maintenance jobs with the integration of the machine's dynamic speed variation technique into the nonswitching flow shop, where the objective is to minimize total energy consumption (TEC).

Table 1. The notation used to formulate the problem

\begin{tabular}{|c|c|}
\hline Indices: & \\
\hline $\begin{array}{l}\mathrm{i} \\
\mathrm{j} \\
k, k^{\prime} \\
\mathrm{l} \\
s\end{array}$ & $\begin{array}{l}\text { Index of jobs } \\
\text { Index of machines } \\
\text { Indices of the position in each machine } \\
\text { Index of the batch in each machine } \\
\text { Index of speed level }\end{array}$ \\
\hline $\begin{array}{l}\text { Sets: } \\
\mathrm{J} \\
\mathrm{M} \\
\mathrm{O}_{\mathrm{i}} \\
\mathrm{BH}_{\mathrm{l}, \mathrm{j}}\end{array}$ & $\begin{array}{l}\text { set of jobs; } J=\left\{J_{1}, J_{2}, \ldots, J_{n}\right\} \\
\text { set of machines; } M=\left\{M_{1}, M_{2}, \ldots, M_{m}\right\} \\
\text { set of the operations of } J_{i} ; O_{i}= \\
\left\{O_{i, 1}, O_{i, 2}, \ldots, O_{i, m}\right\} O_{i, j} \text { is the operation of } \\
J_{i} \text { in } M_{j} \\
\text { set of the batches in the lth batch in } \\
\text { machine } M_{j}\end{array}$ \\
\hline Parameters: & \\
\hline $\mathrm{n}$ & Number of jobs \\
\hline $\mathrm{m}$ & $\begin{array}{l}\text { Numbre of machines } \\
\text { Numbre of speed level }\end{array}$ \\
\hline $\mathrm{w}_{i, j}$ & $\begin{array}{l}\text { The required workload of the job } i(1 \leq \\
i \leq n) \text { in the machine } j(1 \leq j \leq m)\end{array}$ \\
\hline$V_{s}$ & $\begin{array}{l}\text { Processing speed of a machine operating } \\
\text { at a speed level s. }\end{array}$ \\
\hline$P_{i, j}$ & $\begin{array}{l}\text { The processing power of each operation } \\
\mathrm{O}_{\mathrm{i}, \mathrm{j}} \text { in machine } \mathrm{j} \text {. }\end{array}$ \\
\hline $\mathrm{TBF}_{\mathrm{j}}$ & $\begin{array}{l}\text { The period between two consecutive } \\
\text { unavailability intervals in } \mathrm{M}_{\mathrm{j}}\end{array}$ \\
\hline $\mathrm{PM}_{\mathrm{j}}$ & The maintenance time of the machine $M_{j}$ \\
\hline $\mathrm{Z}$ & An infinite integer \\
\hline$C_{\max }$ & $\begin{array}{l}\text { The makespan, which corresponds to the } \\
\text { maximum execution time of all jobs }\end{array}$ \\
\hline $\mathrm{P}_{0}$ & The common power, consumed by \\
\hline
\end{tabular}

'Corresponding author: Sadiqiassia@gmail.com 


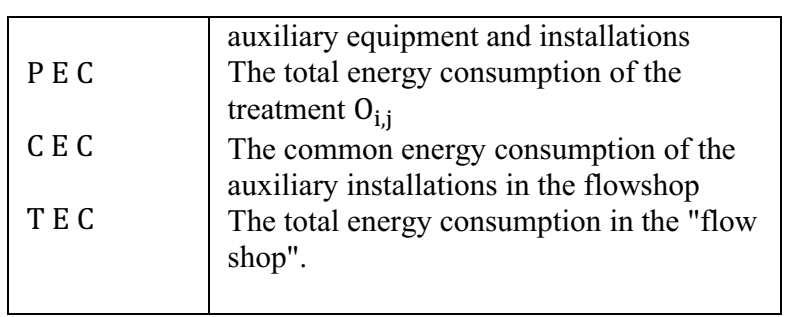

- All jobs are available at the beginning of the scheduling horizon,

- The optimal job sequences are not necessarily identical when the unavailability constraint is taken into account, even for flow shop workshops with two machines. Thus, the non-displacement scheduling is considered in this study.

- The machines can handle jobs at different speed levels, which are selected from a set of levels S.

- Either $v_{S}(1 \leq s \leq S)$ represents the processing speed of a machine operating at the speed level $s$.

\section{Modelling of the problem $\mathrm{Fm} \mid \mathbf{n r}-$ FI $\left.\right|_{\text {TEC }}$}

The first case, where unavailability intervals are set periodically, is referred to as follows:

- Unavailability intervals or maintenance periods are fixed periodically, is noted $\mathrm{Fm}|\mathrm{nr}-\mathrm{FI}|_{\mathrm{TEC}}$.

- The time between two consecutive unavailability intervals in $\mathrm{M}_{\mathrm{j}}$ is $\mathrm{TBF}_{\mathrm{j}}$ and the maintenance time is $\mathrm{PM}_{\mathrm{j}}$.

- The lth unavailability interval can be calculated as follows: lth $=\left[l \mathrm{TBF}_{\mathrm{j}}+(\mathrm{l}-1) \mathrm{PM}_{\mathrm{j}}, \mathrm{l}\left(\mathrm{TBF}_{\mathrm{j}}+\right.\right.$ $\left.\mathrm{PM}_{\mathrm{j}}\right)$ ].

Minimize

$\sum_{i=1}^{n} \sum_{j=1}^{\mathrm{m}} \sum_{k=1}^{\mathrm{n}} \sum_{s=1}^{S} \frac{\mathrm{w}_{i, j} \cdot \mathrm{P}_{\mathrm{i}, \mathrm{j}, \mathrm{s}}}{V_{s}} \cdot \mathrm{x}_{\mathrm{i}, \mathrm{j}, \mathrm{k}, \mathrm{s}}+\mathrm{P}_{0} \cdot C_{\max }$

S.t

$\sum_{i=1}^{\mathrm{n}} \mathrm{x}_{\mathrm{i}, \mathrm{j}, \mathrm{k}, \mathrm{s}}=1 \quad ; \forall \mathrm{j}, \mathrm{k}, \mathrm{s}$

$\sum_{k=1}^{\mathrm{n}} \mathrm{x}_{\mathrm{i}, \mathrm{j}, \mathrm{k}, \mathrm{s}}=1 \quad ; \forall \mathrm{j}, \mathrm{i}, \mathrm{s}$

Constraints (1) and (2) ensure that each job can only be placed at one position in the sequence of each machine, and that only one job can be placed at each position, respectively.

$\sum_{S=1}^{S} \frac{\mathrm{w}_{k, j}}{V_{S}}=\sum_{i=1}^{\mathrm{n}} \sum_{S=1}^{S} \mathrm{x}_{\mathrm{i}, \mathrm{j}, \mathrm{k}, \mathrm{s}} \cdot \frac{\mathrm{w}_{i, j}}{V_{S}} ; \forall \mathrm{k}, \forall \mathrm{j}, \forall \mathrm{s}$

The constraint (3) specifies the processing time of the operation $O_{k, j}$.

$$
\mathrm{C}_{\mathrm{k}, \mathrm{j}}=\mathrm{S}_{\mathrm{k}, \mathrm{j}}+\sum_{s=1}^{S} \frac{\mathrm{w}_{k, j}}{V_{s}} \quad ; \forall \mathrm{j}>1, \forall \mathrm{k}
$$

The constraint (4) establishes the link between the start time and the end time of $O_{k, j}$.

$\mathrm{S}_{1,1}=0$

$\mathrm{S}_{\mathrm{k}, \mathrm{j}} \geq \mathrm{C}_{\mathrm{k}-1, \mathrm{j}}$

$; \forall \mathrm{j}, \forall \mathrm{k} \geq 2$

Constraints (5) and (6) ensure that the kth task cannot start before the end time of the previous task in $M_{j}$.

$$
\begin{aligned}
& \left(2-\mathrm{x}_{\mathrm{i}, \mathrm{j}, \mathrm{k}, \mathrm{s}}-\mathrm{x}_{\mathrm{i}, \mathrm{j}+1, \mathrm{k}^{\prime}, \mathrm{s}}\right) Z \geq \mathrm{S}_{\mathrm{k}, \mathrm{j}}+\sum_{s=1}^{S} \frac{\mathrm{w}_{i, j}}{V_{s}}-\mathrm{S}_{\mathrm{k}^{\prime}, \mathrm{j}+1} \\
& ; \forall \mathrm{j}<\mathrm{m}, \mathrm{i}, \mathrm{k}, \mathrm{k}^{\prime}, \mathrm{s}
\end{aligned}
$$

The constraint (7) ensures that the start time of the task i in $M_{j+1}$ is not earlier than its end time in $M_{j}$.

$$
\begin{aligned}
& \mathrm{C}_{\mathrm{k}, \mathrm{j}}=\mathrm{e}_{\mathrm{k}, \mathrm{j}}+\left(\mathrm{PM}_{\mathrm{j}}+\mathrm{TBF}_{\mathrm{j}}\right) \sum_{k^{\prime}=1}^{k-1} \mathrm{~g}_{\mathrm{k}^{\prime}, \mathrm{j}}+ \\
& \left(\mathrm{PM}_{\mathrm{j}}+\mathrm{TBF}_{\mathrm{j}}\right) \sum_{k^{\prime}=1}^{k-1} \mathrm{q}_{\mathrm{k}, \mathrm{j}} ; \forall \mathrm{j}, \forall \mathrm{k} \geq 1 \\
& \mathrm{C}_{1, \mathrm{j}}=\mathrm{e}_{1, \mathrm{j}}+\left(\mathrm{PM}_{\mathrm{j}}+\mathrm{TBF}_{\mathrm{j}}\right) \mathrm{q}_{1, \mathrm{j}} ; \forall \mathrm{j}
\end{aligned}
$$

Constraints (8) and (9) represent that the arrival time of $O_{k, j}$ is equal to the sum of the elapsed time of $O_{k, j}$ and the times of the previous batches $O_{k, j}$, including actual and empty batches.

$$
\mathrm{q}_{\mathrm{k}, \mathrm{j}} \leq \mathrm{g}_{\mathrm{k}-1, \mathrm{j}} \quad ; \forall \mathrm{j}, \forall \mathrm{k}>1
$$

The constraint (10) ensures that no empty batches exist between $O_{k-1, j}$ and $O_{k, j}$ when $O_{k-1, j}$ is not the last task of a real batch.

$$
\mathrm{e}_{\mathrm{k}, \mathrm{j}} \geq \sum_{S=1}^{S} \frac{\mathrm{w}_{k, j}}{V_{S}} \quad ; \forall \mathrm{k}, \forall \mathrm{j}
$$

The constraint (11) ensures that the elapsed time of the task is greater than its processing time.

$$
\mathrm{e}_{\mathrm{k}, \mathrm{j}} \leq \mathrm{TBF}_{\mathrm{j}} \quad ; \forall \mathrm{k}, \forall \mathrm{j}
$$

The constraint (12) ensures that no jobs can be processed during unavailability intervals.

$$
\mathrm{e}_{\mathrm{k}+1, \mathrm{j}} \geq \mathrm{e}_{\mathrm{k}, \mathrm{j}}+\sum_{s=1}^{S} \frac{\mathrm{w}_{k+1, j}}{V_{s}}-\mathrm{g}_{\mathrm{k}, \mathrm{j}} Z ; \forall \mathrm{k}<\mathrm{n}, \quad \forall \mathrm{j}(13)
$$

The constraint (13) ensures that the elapsed time of $O_{k+1, j}$ is greater than the sum of the processing time of $O_{k+1, j}$ and the elapsed time of $O_{k, j}$ if they're in the same batch.

$$
C_{\max }=\mathrm{C}_{\mathrm{n}, \mathrm{m}}
$$

The constraint (14) confirms that the makepan is equal to the completion time of the machine's nth task.

$\mathrm{x}_{\mathrm{i}, \mathrm{j}, \mathrm{k}, \mathrm{s}}, \mathrm{g}_{\mathrm{k}, \mathrm{j}}$ are of the variables binary

$\mathrm{q}_{\mathrm{k}, \mathrm{j}}$ is a complete

$\frac{\mathrm{w}_{k, j}}{V_{s}}, \mathrm{C}_{\mathrm{k}, \mathrm{j}}, \mathrm{S}_{\mathrm{k}, \mathrm{j}}, \mathrm{e}_{\mathrm{k}, \mathrm{j}} \geq 0$ 


\section{Modelling of the problem $\mathrm{Fm} \mid \mathrm{nr}-$ $\left.\mathrm{CI}\right|_{\text {TEC }}$}

\author{
Minimize $\quad F c t O b j$ \\ S.t
}

Constraint sets (1)-(5) and constraint set (7) are the same with the model 1.

$\mathrm{S}_{\mathrm{k}, \mathrm{j}} \geq \mathrm{C}_{\mathrm{k}-1, \mathrm{j}}+\mathrm{PM}_{\mathrm{j}} \cdot \mathrm{y}_{\mathrm{k}, \mathrm{j}} \quad ; \forall \mathrm{j}, \forall \mathrm{k} \geq 2$

The constraint (18) ensures that the operation $O_{k, j}$ must not start before the sum of the end time of the immediate previous job in $M_{j}$ and the possible maintenance time.

$\mathrm{b}_{1, \mathrm{j}}=0$

$; \forall \mathbf{j}$

$\mathrm{y}_{1, \mathrm{j}}=0$

$; \forall \mathbf{j}$

Constraints (19) and (20) specify the initial state of the system.

$$
\begin{array}{ll}
\mathrm{a}_{\mathrm{k}, \mathrm{j}}=\mathrm{b}_{\mathrm{k}, \mathrm{j}}+\sum_{s=1}^{S} \frac{\mathrm{w}_{k, j}}{V_{s}} & ; \forall \mathrm{k}, \forall \mathrm{j} \\
\mathrm{b}_{\mathrm{k}+1, \mathrm{j}}=\mathrm{a}_{\mathrm{k}, \mathrm{j}}\left(1-\mathrm{Y}_{\mathrm{k}+1, \mathrm{j}}\right) & ; \forall \mathrm{j}, \mathrm{k} \leq \mathrm{n}
\end{array}
$$

Constraints (21) and (22) specify the age of the machines before and after each operation $O_{k, j}$, respectively.

$$
\begin{aligned}
& \mathrm{a}_{\mathrm{k}, \mathrm{j}} \leq \mathrm{TBF}_{\mathrm{j}} \\
& \frac{\mathrm{w}_{k, j}}{V_{s}}, \mathrm{C}_{\mathrm{k}, \mathrm{j}}, \mathrm{S}_{\mathrm{k}, \mathrm{j}} \geq 0
\end{aligned}
$$

\section{Genetic algorithm for solving the models}

The genetic algorithm begins with a step called genesis in which a generation of initial Pop_Size size population of individuals is generated. For each individual generated, a cost function is calculated in order to define the adaptation score of the individuals during the selection process. These individuals evolve through the application of crossing according to a probability Pc. Subsequently, the children obtained undergo an inversion at the level of the genes with a probability of mutation Pm. These three phases of evolution allow with a great chance to produce a new population better than that of the previous generation.

With each new generation, the new populations are increasing and a loop is made as long as the evaluation considers that the solution is not yet optimal. Figure 1 shows the general mechanism of genetic research.
Generate an initial population

Build the scheduling corresponding to the production plan

Calculate the fitness for the solution

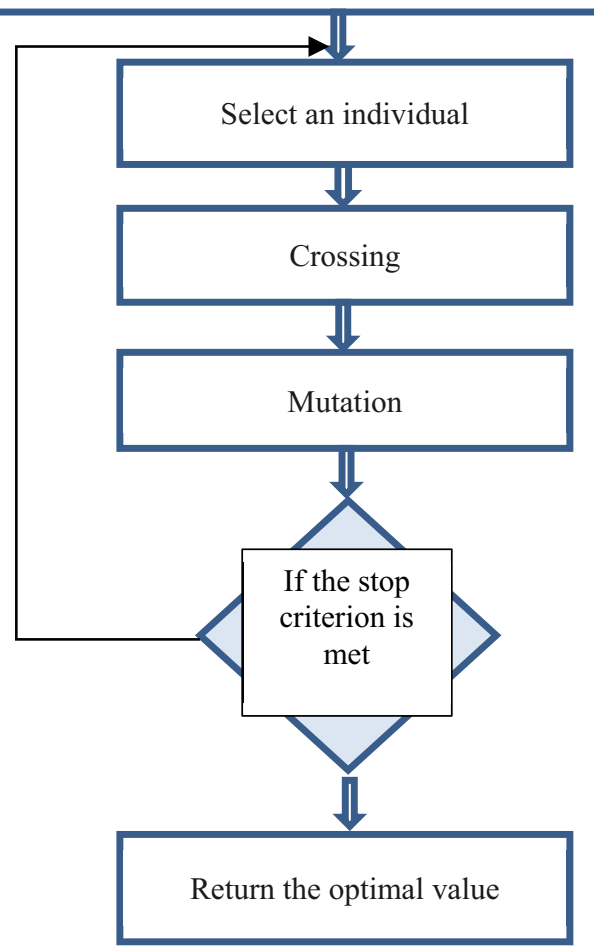

Figure 1. General mechanism of genetic algorithms

The pseudo-code of genetic algorithm :

In order to solve our problem of integrating the planning and ordering of production systems, we present in the following the algorithm of the figure 2 which contains the main stages of the genetic algorithm.

The research begins by initializing a population of individuals who will be called Popsize (population size), $\mathrm{Pc}$ is the percentage of growth, $\mathrm{Pm}$ is the percentage of mutation, max_iteration is the maximum number of iterations. The genetic algorithm stops when the maximum number of iterations is reached. Among the major difficulties of the genetic algorithm is the good choice of the values of the Popsize, Pc, Pm and max_iteration parameters. 


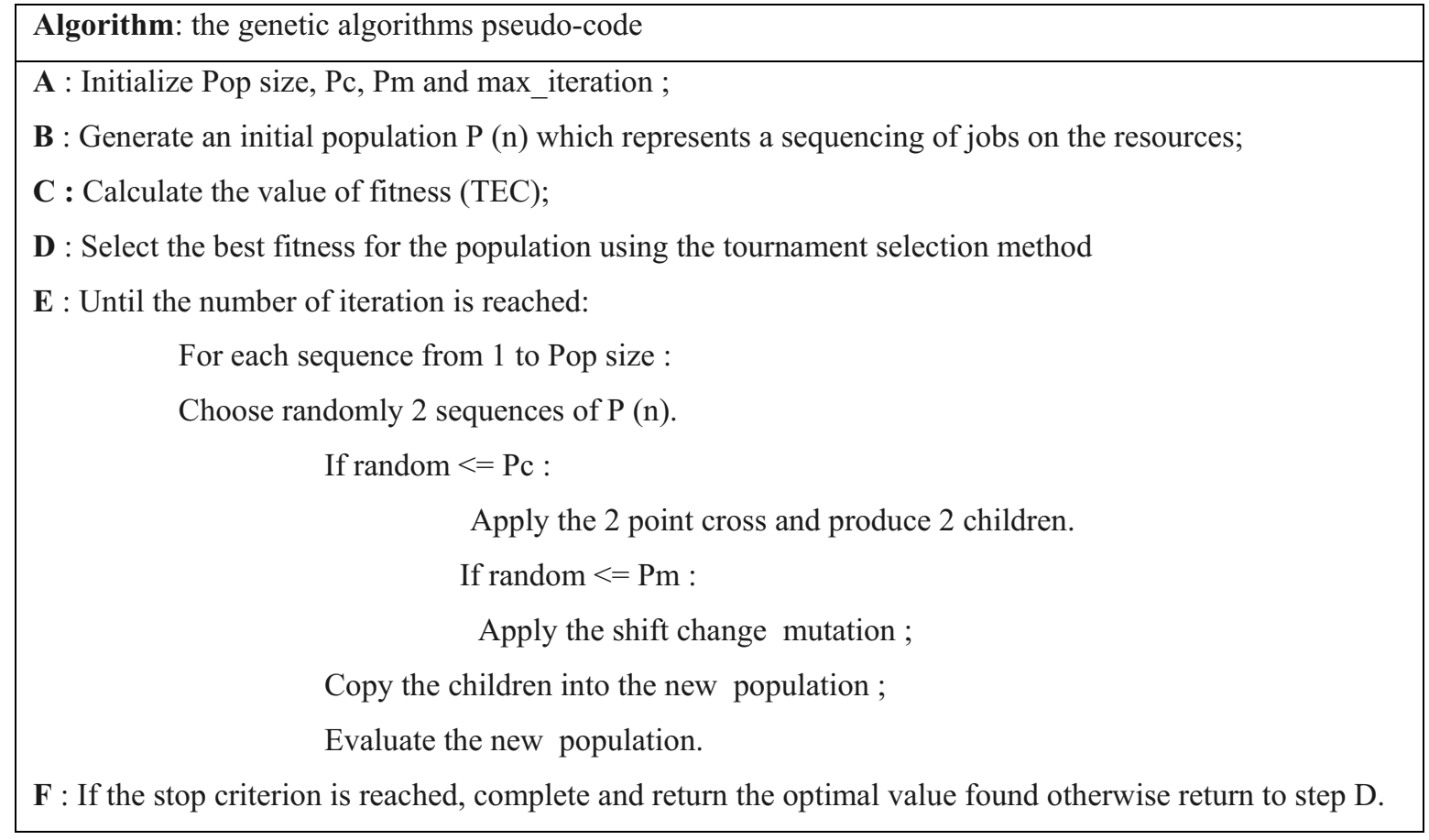

\section{Conclusion}

This work concerns the integrated scheduling of production and maintenance tasks under energy constraints. To our knowledge and according to the literature review, the documents dealing with production and maintenance scheduling do not take into account energy constraints. In the literature, two types of unavailability constraints are examined. In the first case, the unavailability intervals are fixed periodically and known in advance. In the second case, the intervals are flexible and the continuous working time of the machines cannot exceed the maximum authorised time.

We solved these problems with two models for programming mixed binary integers. MILPs are provided with fixed and flexible maintenance types to derive optimal schedules in order to minimize total energy consumption (TEC). The performance of the proposed mixed binary integer programming models is evaluated based on the genetic algorithm (GA). A comparative study of the results provided with those available in the literature proved the performance of the model developed.

\section{References}

1. EIA, 2013. International Energy Outlook 2013 (Online). www. eia . gov / forecasts / ieo / pdf / 0484 ( 2013 ) . pdf. Accessed on 5 May 2018.

2. CSY, 2016. China Statistical Yearbook 2015 (Online). www. stats. gov .cn / tjsj / ndsj / 2016/ indexeh. htm . Accessed on 5 May 2018.

3. Wang S, Wang X, Yu J, Ma S, Liu M, Bi-objective identical parallel machine scheduling to minimize total energy consumption and makespan, Journal of Cleaner Production (2018), doi: 10.1016/j.jclepro.2018.05.056.

4. Ding J., Song S., Zhang R., Chiong R., Wu C. (2016a) Parallel machine scheduling under time-ofuse electricity prices: new models and optimization approaches. IEEE Transactions on Automation Science and Engineering, 13(2): 1138-1154. 